\title{
Comprehensive Left Ventricular Mechanics Analysis by Speckle Tracking Echocardiography in COVID-19
}

\author{
Francisco J. González-Ruiz ${ }^{*}$, Emmanuel A. Lazcano-Díaz¹, Zuilma Y. Vásquez-Ortiz², \\ Fernanda Bernal-Ceballos ${ }^{3}$, Rodrigo Gopar-Nieto' ${ }^{1}$, Consuelo Orihuela-Sandoval ${ }^{2}$, \\ José P. Hernández-Reyes ${ }^{2}$, Edgar García-Cruz ${ }^{1}$, Eduardo Bucio-Reta1 ${ }^{1}$, Ángel Ramos-Enríquez¹, \\ Luis A. Cota-Apodaca1, Luis Efren-Santos' ${ }^{1}$, Blanca Estela Broca-García ${ }^{4}$, Daniel Manzur-Sandoval1, \\ Efrén Melano-Carranza1, Fernandez de la Reguera Guillermo', Gustavo Rojas-Velasco1, \\ Francisco Baranda-Tovar1
}

\begin{abstract}
${ }^{1}$ Department of Cardiovascular Critical Care, National Institute of Cardiology “Dr. Ignacio Chávez”, México City, México ${ }^{2}$ Department of Echocardiography, National Institute of Medical Science and Nutrition “Dr. Salvador Zubirán”, México City, México ${ }^{3} \mathrm{PhD}$ Program, National University of Mexico (UNAM), México City, México ${ }^{4}$ Cardiovascular Diseases Department, National Institute of Cardiology “Dr. Ignacio Chávez”, México City, México Email: *brainhead08@hotmail.com
\end{abstract}

How to cite this paper: González-Ruiz, F.J., Lazcano-Díaz, E.A., Vásquez-Ortiz, Z.Y., Bernal-Ceballos, F., Gopar-Nieto, R., Orihuela-Sandoval, C., Hernández-Reyes, J.P., García-Cruz, E., Bucio-Reta, E., RamosEnríquez, A., Cota-Apodaca, L.A., EfrenSantos, L., Broca-García, B.E., ManzurSandoval, D., Melano-Carranza, E., de la Reguera Guillermo, F., Rojas-Velasco, G., Baranda-Tovar, F. (2021) Comprehensive Left Ventricular Mechanics Analysis by Speckle Tracking Echocardiography in COVID-19. World Journal of Cardiovascular Diseases, 11, 113-125.

https://doi.org/10.4236/wjcd.2021.112013

Received: January 12, 2021

Accepted: February 16, 2021

Published: February 19, 2021

Copyright $\odot 2021$ by author(s) and Scientific Research Publishing Inc. This work is licensed under the Creative Commons Attribution International License (CC BY 4.0). http://creativecommons.org/licenses/by/4.0/

\begin{abstract}
Background: Cardiac involvement and the consequences of inflammation induced by SARS-CoV2 infection could have catastrophic long-term consequences. Left ventricular mechanics could identify a specific pattern of myocardial fiber damage in patients infected with COVID-19. To our knowledge there are no publications referring to the global description of ventricular mechanics in patients with COVID-19. Objective: To describe left ventricular mechanics in hospitalized patients with COVID-19. Methods: In this cross-sectional study, we included 40 hospitalized patients with confirmed diagnostic of COVID-19, from April 11, 2020, to September 6, 2020. Demographic and laboratory data, clinical and echocardiographic characteristics were collected, as well as events during hospitalization. Left ventricular deformation was analyzed and reported. Results: Subclinical dysfunction was observed in $82.5 \%$ (left ventricular longitudinal strain [LVGLS] $-17.05 \%$ and global circumferential strain [GCS] $-18.6 \%$ ) of the patients, likewise, the mean twist and apical rotation were preserved, and even increased as part of the compensating mechanism to maintain the ejection fraction. Conclusion: In patients hospitalized with COVID-19, despite having a normal left ventricular ejection fraction, subclinical myocardial damage was found, manifested by a decrease in Global Longitudinal Strain (GLS) and Global Circumferential Strain (GCS). This behavior is similar to that of cardiomyopathies in the early
\end{abstract}


stage of the disease, and given the pathophysiological mechanisms involved in the disease, its long-term consequences should be monitored and evaluated.

\section{Keywords}

COVID-19, Speckle Tracking Echocardiography, Myocarditis, Cardiomyopathy, Cardiac Mechanics, Strain, Myocardial Damage, Deformation Imaging, Myocardial Strain

\section{Introduction}

Currently, the pandemic caused by the severe acute respiratory syndrome coronavirus 2 (SARS-Cov-2) continues to be a global threat due to its high rate of morbidity and mortality, its involvement of multiple organs and systems, including the cardiovascular system. Some studies have reported the prevalence of myocardial damage in hospitalized patients for coronavirus disease 2019 (COVID-19), which varies between $12 \%$ - 27\% [1] [2] [3]. Myocardial damage caused by SARS-Cov2 can be caused by direct damage, prothrombotic effects associated with the infectious process and the effects of inflammation [4] [5]. Cardiac involvement has been documented by the increase in cardiac biomarkers (specifically troponin $\mathrm{T}$ and atrial natriuretic peptide) showing an increased risk of mortality and cardiac arrhythmias, especially in those patients with chronic cardiovascular conditions [6]. The diagnosis of myocarditis represents a challenge and early identification could lead to prompt intervention in an effort to reduce complications and long-term sequelae.

Cardiac magnetic resonance imaging is considered the gold standard for the diagnosis of myocarditis with an estimated accuracy rate of $79 \%$. The correlation of clinical symptoms and the presence of late gadolinium enhancement in typical patterns together with evidence of myocardial edema on T2 images, ensure the diagnosis [7] [8]. However, the difficulties for the transfer of infected patients, and even more those who are in critical condition, have limited its use. In the general evaluation of myocardial damage, traditionally the use of echocardiography has been based on the determination of the volumes and the ejection fraction, which have significant interobserver variability [8] [9]. However, the use of ventricular mechanics has emerged as a quantitatively powerful and highly accurate tool for global and regional assessment, as well as being a predictor of cardiovascular events [10] [11] [12] [13].

Ventricular mechanics have been widely used in the cardiovascular context, but it is not limited only to these conditions. In sepsis, alterations in Left Ventricular Longitudinal Strain (LVGLS) and Right Ventricular Longitudinal Strain (RVGLS) have been described in $69 \%$ and $72 \%$ of patients respectively, of which only $33 \%$ of patients had a reduction in the Left Ventricular Ejection Fraction (LVEF) and $32 \%$ of the right ventricle, with a global longitudinal strain as a cut-off point of less than $-13 \%$ as a marker of mortality in septic shock in inten- 
sive care, outside the COVID-19 context [14] [15]. Recently, a study by Li et al. [16] evaluated the prognostic value of Right Ventricular Longitudinal Strain (RVLS) in patients hospitalized for COVID-19, in which non-surviving patients presented right ventricular dysfunction and dilatation; furthermore, an RVLS $-23 \%$ predicted a higher risk of death, regardless of sex and Acute Respiratory Distress Syndrome (ARDS).

The objective of this study was to describe the abnormalities of ventricular mechanics in patients infected with COVID by echocardiography with extended specialized analysis admitted to the intensive care unit of our hospital. The authors' hypothesis has focused on the myocardial involvement having a specific pattern of myocardial damage that can prevail over time and establish itself as an inflammatory cardiomyopathy.

\section{Methods}

Study design: This is a cross-sectional study that included 40 patients with confirmed SARS-CoV2 infection, admitted to Cardiovascular Critical Care Unit of National Institute of Cardiology Dr. Ignacio Chávez from April 11, 2020, to September 6, 2020 in which transthoracic echocardiography and ventricular mechanics were assessed. The inclusion criteria were: patients over 18 years of age, with moderate-severe respiratory symptoms, requiring mechanical ventilation and/or non-invasive ventilation with poor prognostic markers (D-dimer, ferritin levels, lymphopenia) with test of SARS-CoV2 confirmed by PCR. All patients were treated in individual isolated rooms. Those patients with any pre-existing clinical conditions (valvular, ischemic heart and congenital heart disease, chronic kidney disease or COPD) were excluded. Of the patients included, 1 patient had pulmonary embolism and one patient had Takotsubo syndrome type 1 .

Demographic characteristics, clinical and laboratory data of each patient were collected from electronic medical records. This study was conducted according to the principles of the Declaration of Helsinki [17] and was approved by the Institutional Ethics Committee. Written informed consent was waived by the ethics commission of the designated hospital for patients with emerging infectious diseases.

\section{Echocardiographic assessment/Transthoracic echocardiography}

All studies were performed with a new generation General Electric echocardiography equipment, Vivid E9 with XDclear, with an M5Sc-D (1.5 - 4.6 MHz) sector cardiac and a $4 \mathrm{~V}-\mathrm{D}$ volumetric probes $(1.5-4.0 \mathrm{MHz})$. The patients underwent a transthoracic echocardiogram, according to the availability of equipment and personnel to perform it. The median number of days from patient admission to echocardiogram was 2 days (interquartile range 0 - 5). The transthoracic echocardiogram was performed by a certified echocardiographer cardiologist, following the recommendations of the American Society of Echocardiography [17]. 
Two-dimensional echocardiography was used to measure left ventricular enddiastolic diameter, left ventricular end-systolic diameter, end-diastolic septal thickness, and ejection fraction according to the American Society of Echocardiography recommendations. Left ventricular outflow track was obtained by pulsed-wave (PW) tissue Doppler imaging. Regional wall motion of the 16 segments was scored individually on the basis of the motion and systolic thickening. Segment scores were as follows: $1=$ normal, 2 =hypokinesis, $3=$ akinesis, $4=$ dyskinesis, and $5=$ aneurysmal changes. The wall motion score index was the sum of all the segment scores divided by the number of segments assessed [18]. Right Ventricle (RV) function was determined from apical 4-chamber view. Right ventricular function was assessed by Tricuspid Annular Plane Systolic Excursion (TAPSE), RV Fractional Area Change (RVFAC) and tricuspid lateral annular systolic velocity $\left(S^{\prime}\right)$ using tissue doppler imaging from the apical 4chamber view [18].

\section{Speckle-tracking echocardiography}

Measurements were taken and analyzed according to the latest recommendations of the American Society of Echocardiography. For the analysis of left ventricular mechanics, two cardiac cycles were taken in conventional short axis two-dimensional views at the height of the mitral valve and at the height of the apex (for radial, circumferential, rotation, twist, untwist and torsion) and apical slices. In four, three and two chambers focused on the left ventricle (for global longitudinal deformation and its derivatives), all with a frame rate of 60 - 80 per second. The tracing for bright spot analysis was performed according to the recommendations of the American Society of Echocardiography. Post-processing analysis was done with EchoPAC Version 3.

Strain was defined as a unit that expresses the total myocardial deformation during the cardiac cycle expressed as a percentage. Global Longitudinal Strain (GLS) was defined as deformation of the left ventricle in the longitudinal direction; is the percentage of shortening of the myocardial fiber from the base to the apex. Global Circumferential Strain (GCS) was defined as the percentage of myocardial fiber shortening tangential to the long axis. Left ventricular twist was defined as the algebraic subtraction between apical rotation and basal rotation of the left ventricle. Torsion is the normalization of the twist due to the greater length of the left ventricle. By convention, apical rotation has positive and negative baseline values [27].

After the analysis was performed and accepted, the curves were given for all the variables studied and exported to the spreadsheet. Global values were defined as the average of the analyzed segments (Figure 1 and Figure 2).

\section{Statistical analysis}

We used Shapiro-Wilk's normality test for continuous variables. After assessing their distribution we reported them as mean and standard deviation, if they were parametric, and median and interquartile range, if they were non-parametric. Comparisons among continuous variables were made with Student's $t$ test or 

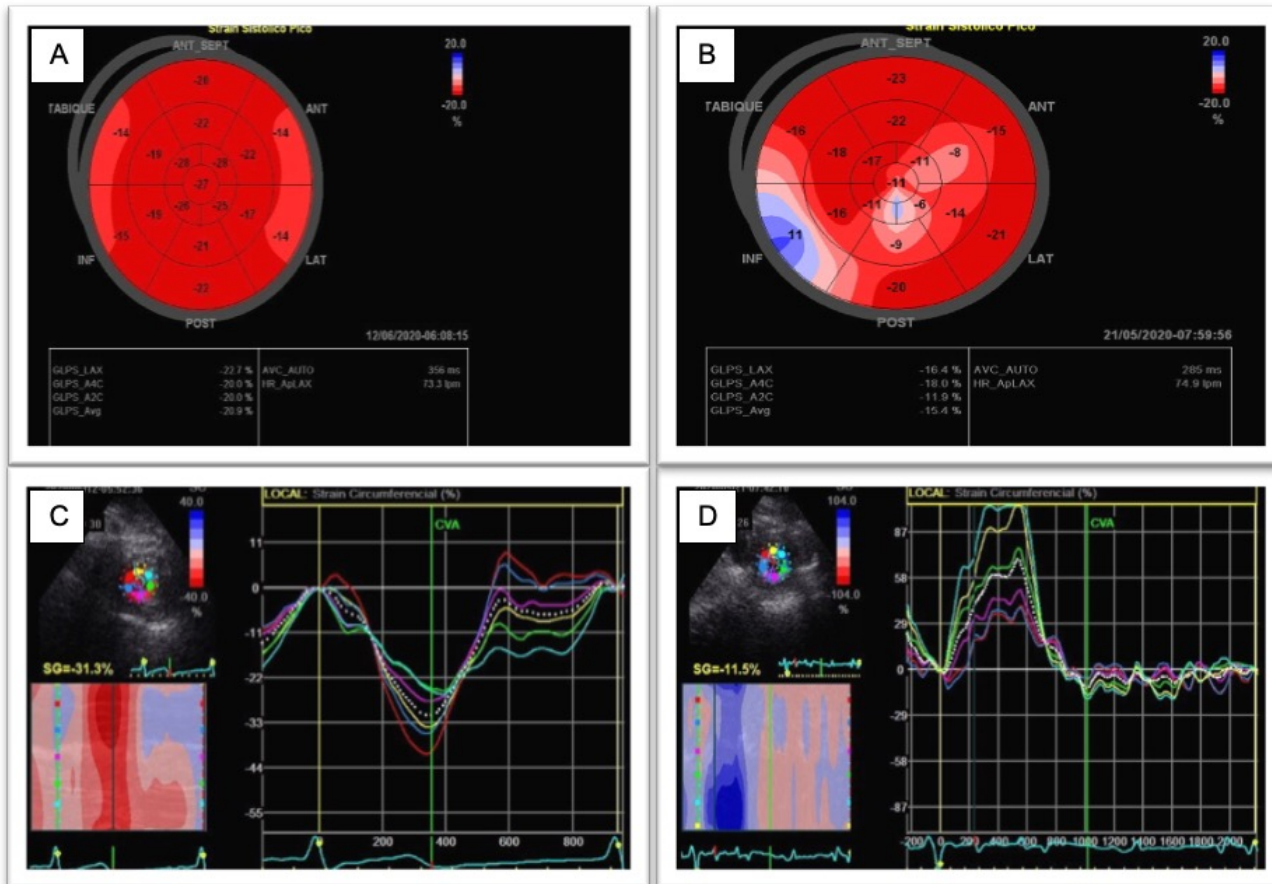

Figure 1. Schematic representation of global longitudinal strain in an unaffected patient (A) from an affected patient (B). Normal Global circumferential strain (C), compared with an abnormal one in a patient infected with covid-19 (D). Note positive deformation in abnormal circumferential strain.
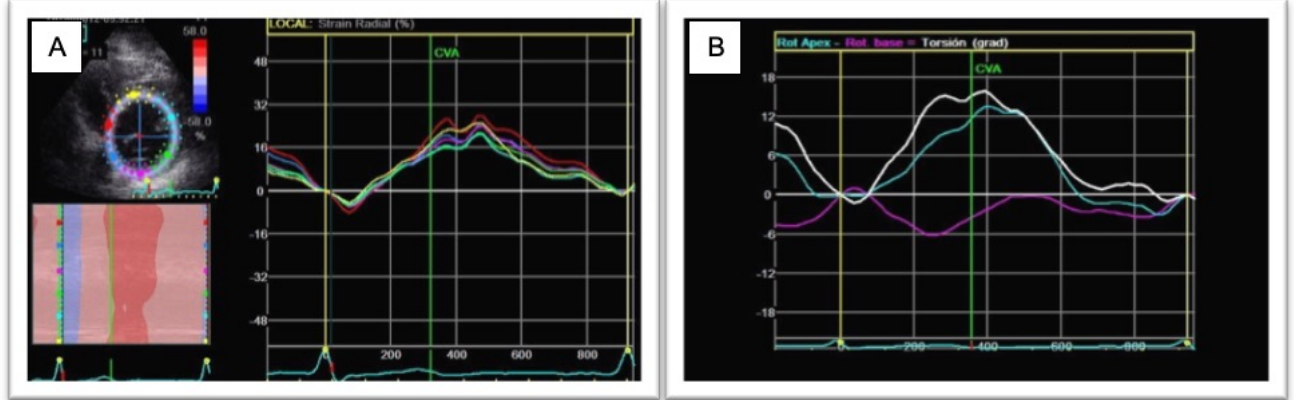

Figure 2. Schematic representation of radial strain (A) and normal torsion (B) in patients infected with covid-19.

Mann-Whitney's U test, according to the distribution of each variable. Categorical variables were described with frequencies and percentages; for comparisons we used $\chi^{2}$ test and Fisher's exact test, as appropriate according to expected values in the contingence tables. We performed a Cox-regression model, adjusted by age and gender, to assess the variables that predicted mortality and mechanical ventilation. We performed Kaplan-Meier graphs in order to compare mortality among groups. All statistical analyses were considered significant with a $\mathrm{p}$ value $<0.05$. Statistical analysis was made with STATA V14.

\section{Results}

This study included 40 patients, most of them were male $(77.5 \%)$ and had a 
mean age of $56 \pm 11$ years. Abnormal strain was detected in 33 patients (82.5\%). Survival among the population was $60 \%$ and the most common disease was diabetes (45\%). Table 1 shows the distribution of demographic and laboratory data divided by survival and non-survivors. The differences detected among groups were diabetes, maximal troponin, D-dimer, creatinine and hemoglobin.

Table 1. Patient characteristics, laboratory findings and comorbidities.

\begin{tabular}{|c|c|c|c|c|}
\hline Variable & Total $(n=40)$ & Survivors $(n=24)$ & Non-survivors $(n=16)$ & $\mathrm{p}$ \\
\hline $\begin{array}{l}\text { Age (years) } \\
\text { Mean } \pm \text { SD }\end{array}$ & $56 \pm 11$ & $54.6 \pm 11.6$ & $58.1 \pm 10.1$ & 0.33 \\
\hline $\begin{array}{c}\text { BMI }\left(\mathrm{kg} / \mathrm{m}^{2}\right) \\
\text { Median (IQR) }\end{array}$ & $27.3(25-30.5)$ & $26.5(24.9-30.5)$ & $28.2(25.5-31.3)$ & 0.37 \\
\hline $\begin{array}{l}\text { Weight }(\mathrm{kg}) \\
\text { Median (IQR) }\end{array}$ & $75(70-85)$ & $73.5(70-85.5)$ & $77.5(70-83.5)$ & 0.81 \\
\hline $\begin{array}{l}\text { Women } \\
\mathrm{n}(\%)\end{array}$ & $9(22.5)$ & $4(16.7)$ & $5(31.2)$ & \multirow{2}{*}{0.44} \\
\hline $\begin{array}{l}\text { Men } \\
\mathrm{n}(\%)\end{array}$ & $31(77.5)$ & $20(83.3)$ & $11(68.8)$ & \\
\hline $\begin{array}{l}\text { Hypertension } \\
\mathrm{n}(\%)\end{array}$ & $10(25)$ & $6(25)$ & $4(25)$ & 1 \\
\hline $\begin{array}{l}\text { Diabetes } \\
\mathrm{n}(\%)\end{array}$ & $18(45)$ & $6(25)$ & $12(75)$ & 0.00 \\
\hline $\begin{array}{l}\text { Maximal troponin }(\mathrm{pg} / \mathrm{mL}) \\
\text { Median }(\mathrm{IQR})\end{array}$ & $67.6(15.2-127)$ & $36.6(10.1-101)$ & $92(59-242)$ & 0.02 \\
\hline $\begin{array}{c}\text { Troponin at admission }(\mathrm{pg} / \mathrm{mL}) \\
\text { Median (IQR) }\end{array}$ & $35.2(6.5-85)$ & $11.7(5.1-85)$ & $40.2(19-85)$ & 0.23 \\
\hline $\begin{array}{l}\text { Maximal D-dimer }(\mathrm{ng} / \mathrm{mL}) \\
\text { Median (IQR) }\end{array}$ & $0.69(0.51-2.37)$ & $0.61(0.43-0.90)$ & $1.42(0.64-3.37)$ & 0.02 \\
\hline $\begin{array}{c}\text { D-dimer at admission }(\mathrm{ng} / \mathrm{mL}) \\
\text { Median }(\mathrm{IQR})\end{array}$ & $0.61(0.40-0.99)$ & $0.55(0.29-0.64)$ & $0.99(0.60-2.65)$ & 0.00 \\
\hline Maximal ferritine $(\mathrm{ng} / \mathrm{mL})$ & $1091(548-1582)$ & $1170(675-1779)$ & $821(345-1366)$ & 0.25 \\
\hline $\begin{array}{c}\text { Ferritine at admission }(\mathrm{ng} / \mathrm{mL}) \\
\text { Median }(\mathrm{IQR})\end{array}$ & $770(407-1425)$ & $960(531-1779)$ & $509(156-842)$ & 0.02 \\
\hline $\begin{array}{l}\text { Maximal fibrinogen }(\mathrm{g} / \mathrm{L}) \\
\text { Median }(\mathrm{IQR})\end{array}$ & $6.15(5.43-7.1)$ & $6.15(5-7.32)$ & $6.39(5.7-7.1)$ & 0.50 \\
\hline $\begin{array}{c}\text { Fibrinogen at admission }(\mathrm{g} / \mathrm{L}) \\
\text { Median }(\mathrm{IQR})\end{array}$ & $5.36(4.5-6.5)$ & $5.7(4.6-6.7)$ & $5.2(4.5-6.4)$ & 0.53 \\
\hline $\begin{array}{c}\text { Maximal C reactive protein }(\mathrm{mg} / \mathrm{L}) \\
\text { Median }(\mathrm{IQR})\end{array}$ & $238(127-311)$ & $212(95-301)$ & $283(138-371)$ & 0.21 \\
\hline $\begin{array}{c}\mathrm{C} \text { reactive protein at admission }(\mathrm{mg} / \mathrm{L}) \\
\text { Median }(\mathrm{IQR})\end{array}$ & $138(72-266)$ & $163(88-266)$ & $124(59-265)$ & 0.37 \\
\hline $\begin{array}{c}\text { Maximal creatinine }(\mathrm{mg} / \mathrm{dL}) \\
\text { Median }(\mathrm{IQR})\end{array}$ & $1.15(0.7-1.9)$ & $0.96(0.65-1.26)$ & $1.9(0.9-2.8)$ & 0.01 \\
\hline $\begin{array}{c}\text { Creatinine at admission }(\mathrm{mg} / \mathrm{dL}) \\
\text { Median (IQR) }\end{array}$ & $0.9(0.7-1.4)$ & $0.8(0.7-1.1)$ & $1.2(0.8-1.5)$ & 0.01 \\
\hline
\end{tabular}




\section{Continued}

\begin{tabular}{|c|c|c|c|c|}
\hline $\begin{array}{l}\text { Aspartate aminotransferase (U/L) } \\
\text { Median (IQR) }\end{array}$ & $87(63-116)$ & $87(63-122)$ & $87(63-110)$ & 0.78 \\
\hline $\begin{array}{c}\text { Alanin aminotransferase (U/L) } \\
\text { Median (IQR) }\end{array}$ & $83(62-114)$ & $87(70-128)$ & $79(51-100)$ & 0.19 \\
\hline $\begin{array}{c}\text { Total billirrubin }(\mathrm{mg} / \mathrm{dL}) \\
\text { Median }(\mathrm{IQR})\end{array}$ & $0.77(0.54-1.24)$ & $0.82(0.54-1.2)$ & $0.69(0.53-1.34)$ & 0.83 \\
\hline $\begin{array}{l}\text { Hemoglobin at admission }(\mathrm{g} / \mathrm{dL}) \\
\text { Median (IQR) }\end{array}$ & $15(14.2-15.8)$ & $15.2(14.2-16.2)$ & $14.6(14-15.4)$ & 0.13 \\
\hline $\begin{array}{l}\text { Minimal hemoglobin }(\mathrm{g} / \mathrm{dL}) \\
\text { Median (IQR) }\end{array}$ & $9.6(8.6-12.1)$ & $10.4(9.6-13.5)$ & $8.8(7.4-9.7)$ & 0.00 \\
\hline $\begin{array}{l}\text { Hematocrit (\%) } \\
\text { Median (IQR) }\end{array}$ & $29.1(26.1-37.8)$ & $30.9(28.1-40.5)$ & $27.3(22.9-29)$ & 0.00 \\
\hline $\begin{array}{l}\text { Leucocytes }\left(10^{3} / \mu \mathrm{L}\right) \\
\text { Median }(\mathrm{IQR})\end{array}$ & $12.2(8.7-16.8)$ & $11.2(6.5-13.7)$ & $15.8(11.6-18.8)$ & 0.03 \\
\hline $\begin{array}{l}\text { NT-proBNP }(\mathrm{pg} / \mathrm{mL}) \\
\text { Median (IQR) }\end{array}$ & $832(308-2156)$ & $385(148-833)$ & $2214(1043-7646)$ & 0.00 \\
\hline
\end{tabular}

SD: standard deviation; BMI: body mass index; IQR: interquartile range.

Cardiac and inflammation biomarkers (troponin I, NT-proBNP, ferritin, D-dimer, C-reactive protein) were found to be significantly increased in all patients. However, there were differences detected in the values of these between survivors and non-survivors related to the values of maximum troponin, D-dimer, ferritin and creatinine, as well as in patients suffering from diabetes mellitus. The values of the conventional transthoracic two-dimensional echocardiography were within normality, with the exception of the value of the velocity-time index of the left ventricular outflow tract (as a surrogate of the stroke volume) as well as in the fractional change area of the right ventricle, which showed a slight decrease in non-surviving patients, compared to those who survived.

Regarding left ventricular mechanics (Table 2), there are significant findings most likely related to the cardiac involvement of Covid-19 infection and the following are noteworthy: a significant decrease in both groups in the value of global longitudinal strain as well as circumferential strain and increase of the twist value. Although this last parameter shows an increase in its value, among the patients who did not survive and had a decreased value, an associated increase in mortality was found. Radial strain only showed a biphasic pattern.

No significant associations were found with respect to ventricular mechanics values and associated complications during the time of hospitalization (liver and kidney failure, cardiogenic shock), most likely due to the size of the sample of patients studied.

Table 3 shows the outcomes of the patients according to the presences or absence of strain abnormalities. There were no significant differences but MACE were higher among the patients with abnormal strain than in those with normal strain $(69.7 \%$ vs $42.9 \%)$

In order to know the magnitude of the association between the variables with 
Table 2. Echocardiographic measurements.

\begin{tabular}{ccccc}
\hline Variable & $\begin{array}{c}\text { Total } \\
\text { Median (IQR) }\end{array}$ & $\begin{array}{c}\text { Survivors } \\
\text { Median (IQR) }\end{array}$ & $\begin{array}{c}\text { Non-survivors } \\
\text { Median (IQR) }\end{array}$ & p \\
\hline LV diastolic diameter $(\mathrm{mm})$ & $43.5(40-47)$ & $45(40-50)$ & $42(38-44)$ & 0.10 \\
LV systolic diameter $(\mathrm{mm})$ & $25(21-31)$ & $26(20-29)$ & $24(22-31)$ & 0.94 \\
LVOT VTI & $18.2(16.5-21.1)$ & $19.5(17.3-21.2)$ & $17.1(15.3-18.7)$ & 0.04 \\
TAPSE & $21(19.5-23)$ & $21.5(20-24)$ & $20.5(19-23)$ & 0.38 \\
RV basal diameter (mm) & $32.5(30-39)$ & $32(30.5-37)$ & $33.5(30-40)$ & 0.70 \\
RV mid diameter (mm) & $26.5(23.5-31.5)$ & $29(24-32)$ & $25(23-30)$ & 0.32 \\
RV longitudinal diameter (mm) & $69(64-72)$ & $69(65-72)$ & $68(63-73)$ & 0.63 \\
RV FAC & $45(38-50)$ & $48(39-51)$ & $44(30-47)$ & 0.07 \\
LV EF & $63.5(58.5-67.5)$ & $62.5(58.5-67.5)$ & $64.5(59-68)$ & 0.80 \\
LV longitudinal strain & $-17.05(-18.05--16.15)$ & $-17.1(-18.1--16.4)$ & $-16.7(-18--15.7)$ & 0.46 \\
LV radial strain & $7.5(2.85-16.5)$ & $7(2.4-16)$ & $8(3-17.5)$ & 0.95 \\
LV circumferential strain & $-18.6(-23--16.8)$ & $-20(-23.5--17.1)$ & $-17.5(-20--16.2)$ & 0.16 \\
Basal rotation & $-6(-8--3.5)$ & $-6(-8--5)$ & $-4.5(-8.5--2)$ & 0.11 \\
Apical rotation & $9.5(7-12)$ & $10(7.5-11.5)$ & $8.5(2.5-12)$ & 0.35 \\
Twist & $16.5(10.5-22)$ & $16.5(13-22)$ & $15.5(8.5-24)$ & 0.52 \\
\hline
\end{tabular}

LV: left ventricular; IQR: interquartile range; LVOT TVI: left ventricular outflow tract velocity time integral; TAPSE: tricuspid annulus plane systolic excursion; RV: right ventricular; FAC: fractional area change; EF: ejection fraction.

Table 3. Outcomes.

\begin{tabular}{ccccc}
\hline Variable & $\begin{array}{c}\text { Total } \\
(\mathbf{n}=40)\end{array}$ & $\begin{array}{c}\text { Normal strain } \\
(\mathbf{n}=7)\end{array}$ & $\begin{array}{c}\text { Abnormal strain } \\
(\mathbf{n}=33)\end{array}$ & $\mathbf{p}$ \\
\hline Death & $16(40)$ & $3(42.9)$ & $13(39.4)$ & 1 \\
Mechanical ventilation & $21(52.5)$ & $3(42.9)$ & $18(54.5)$ & 0.68 \\
Other infections & $24(60)$ & $3(42.9)$ & $21(63.6)$ & 0.30 \\
MACE & $26(65)$ & $3(42.9)$ & $23(69.7)$ & 0.07 \\
Days in mechanical ventilation & $8(0-19)$ & $11(0-22)$ & $0(0-11)$ & 0.18 \\
Days in CCU & $10(6-21)$ & $12(7-23)$ & $8(3-13)$ & 0.17 \\
Hospitalization days & $16(11-26)$ & $18(12-29)$ & $13(10-16)$ & 0.18 \\
\hline
\end{tabular}

the occurrence of MACE we performed a Cox-regression analysis. We found that LV longitudinal strain, low circumferential strain, low LVOT VTI and low twist were associated with higher MACE but with no statistical significance (Table 4). C reactive protein, troponin and creatinine were significantly associated with MACE. Figure 3 shows a Kaplan-Meier analysis in which we found no significant differences regarding MACE among patients with low and abnormal strain. 
Table 4. Cox-regression model adjusted by age and sex for the prediction of MACE.

\begin{tabular}{cccc}
\hline Variable & HR & p & CI 95\% \\
\hline LV longitudinal strain $<-17.0$ & 1.73 & 0.39 & $0.48-6.16$ \\
Low LV radial strain & 0.66 & 0.32 & $0.25-1.75$ \\
Low circumferential strain & 1.49 & 0.35 & $0.64-3.48$ \\
Low twist & 2.09 & 0.12 & $0.81-5.39$ \\
LVOT VTI $<18$ & 1.39 & 0.45 & $0.57-3.40$ \\
TAPSE $<17 \mathrm{~mm}$ & 6.25 & 0.11 & $0.62-62$ \\
FACVD $<35 \%$ & 2.24 & 0.09 & $0.87-5.72$ \\
C reactive protein $>100 \mathrm{mg} / \mathrm{L}$ & 3.48 & 0.03 & $1.07-11.29$ \\
Troponin I $>40 \mathrm{pg} / \mathrm{mL}$ & 2.60 & 0.04 & $1.01-6.67$ \\
D-dimer $>0.60 \mathrm{ng} / \mathrm{mL}$ & 1.06 & 0.89 & $0.42-2.67$ \\
Creatinine $>0.9 \mathrm{mg} / \mathrm{dL}$ & 2.71 & 0.03 & $1.05-7$ \\
\hline
\end{tabular}

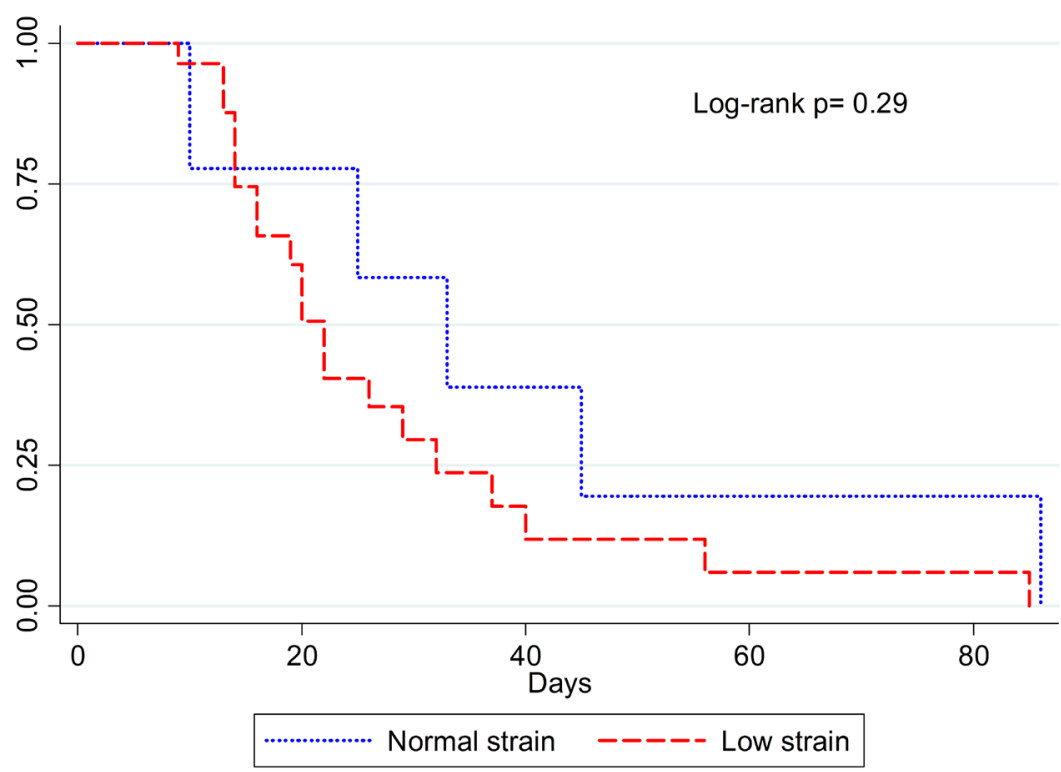

Figure 3. Kaplan-Meier graph for MACE in patients with low and normal strain.

\section{Discussion}

In our study, we found a reduction in global longitudinal strain in most of our population, reflecting a marked compromise of subendocardial fibers. The most significant alterations were those related to longitudinal and circumferential strain, possibly explained by the nature of microthrombotic phenomena in the cardiac vasculature and inflammation or direct damage related to the virus and predict an unfavorable prognosis with significant changes of contractile function and increased mortality in those patients with persistent inflammation [4].

To our knowledge, this is the first study to fully assess myocardial contraction mechanics in patients infected with COVID-19 during the initial hospitalization with the aim to describe and establish a predictable ventricular mechanics pat- 
tern as a consequence of the deleterious effects of the viral infection. The patients included in our case series are relatively homogeneous, with only some demographic differences. All the patients listed in our review had pharmacological measures with effective control of blood pressure and glucose.

Some studies have reported ventricular mechanics in patients with myocarditis have detected a prediction of major adverse clinical events in patients showing alterations in longitudinal and circumferential strain compared with controls [9] [19] [20] [21] and we demonstrate that this pattern remains in myocardial affection due to Covid-19.

Left ventricular function is extremely complex, it is known that the relationship between left ventricular GLS/ejection fraction is linear, [22] while LVGCS contributes twice as much to LVEF [23] and that it is frankly deteriorated in patients with the infection. Torsional deformation also contributes significantly to ventricular function and partly explains why EF remains unchanged [24]. The effects of inflammation persist over time and have been demonstrated in patients discharged from hospital, followed through cardiac magnetic resonance imaging [25].

Such findings could hypothetically assume that in the long-term, these patients could show ventricular remodeling, myocardial fibrosis and heart failure, which can reduce the capacity of performing daily activities and a poor long-term prognosis [26].

For this reason, early identification of alterations in ventricular mechanics would be convenient, allowing early prediction of the impact on cardiac function and timely therapeutic intervention to attenuate the effects of inflammation, in order to avoid permanent damage, not aggravating another pandemic that has afflicted our society for decades, such as congestive heart failure.

\section{Conclusion}

The analysis of left ventricular mechanics in our study of hospitalized patients with COVID-19 showed that despite having a normal LVEF, we demonstrated subclinical myocardial damage manifested by a decrease in GLS and GCS. The behavior is similar to that of cardiomyopathies in the early stage of the disease. Although the sample size was limited, our research clearly shows that COVID-19 infection causes a decrease in the left heart reserve and will most likely have devastating consequences.

\section{Limitations}

The main limitation of this study was the small sample size in a single center. Larger assays are necessary to correlate parameters of inflammation with the echocardiographic findings shown in our investigation.

\section{Conflicts of Interest}

The authors declare no conflicts of interest regarding the publication of this paper. 


\section{References}

[1] Huang, C., Wang, Y., Li, X., et al. (2020) Clinical Features of Patients Infected with 2019 Novel Coronavirus in Wuhan, China. The Lancet, 395, 497-506. https://doi.org/10.1016/S0140-6736(20)30183-5

[2] Zhou, F., Yu, T., Du, R., et al. (2020) Clinical Course and Risk Factors for Mortality of Adult Inpatients with COVID-19 in Wuhan, China: A Retrospective Cohort Study. The Lancet, 395, 1054-1062. https://doi.org/10.1016/S0140-6736(20)30566-3

[3] Guo, T., Fan, Y., Chen, M., et al. (2020) Cardiovascular Implications of Fatal Outcomes of Patients with Coronavirus Disease 2019 (COVID-19). JAMA Cardiology, 5, 811-818. https://doi.org/10.1001/jamacardio.2020.1017

[4] Siripanthong, B., Nazarian, S., Muser, D., Deo, R., Santangeli, P., Khanji, M.Y., et al. (2020) Recognizing COVID-19-Related Myocarditis: The Possible Pathophysiology and Proposed Guideline for Diagnosis and Management. Heart Rhythm, 17, 1463-1471.

[5] Rizzo, P., Vieceli Dalla Sega, F., Fortini, F., Marracino, L., Rapezzi, C. and Ferrari, R. (2020) Covid-19 in the Heart and the Lungs: Could We "Notch" the Inflammatory Storm? Basic Research in Cardiology, 115, Article No. 31. https://doi.org/10.1007/s00395-020-0791-5

[6] Sandoval, Y., Januzzi Jr., J.L. and Jaffe, A.S. (2020) Cardiac Troponin for the Diagnosis and Risk-Stratification of Myocardial Injury in COVID-19: JACC Review Topic of the Week. Journal of the American College of Cardiology, 76, 1244-1258.

[7] Kostakou, P.M., Kostopoulos, V.S., Tryfou, E.S., et al. (2018) Subclinical Left Ventricular Dysfunction and Correlation with Regional Strain Analysis in Myocarditis with Normal Ejection Fraction. A New Diagnostic Criterion. International Journal of Cardiology, 259, 116-121. https://doi.org/10.1016/j.ijcard.2018.01.058

[8] Farzaneh-Far, A. and Romano, S. (2020) Imaging and Impact of Myocardial Strain in Myocarditis. JACC: Cardiovascular Imaging, 13, 1902-1905.

[9] Hsiao, J.-F., Koshino, Y., Bonnichsen, C.R., et al. (2013) Speckle Tracking Echocardiography in Acute Myocarditis. The International Journal of Cardiovascular Imaging, 29, 275-284. https://doi.org/10.1007/s10554-012-0085-6

[10] Beata, U.Z., Marta, M., Robert, R. and Pawel, K. (2020) Myocarditis Successfully Diagnosed and Controlled with Speckle Tracking Echocardiography. Cardiovascular Ultrasound, 18, Article No. 19. https://doi.org/10.1186/s12947-020-00203-4

[11] Becker, M., Bilke, E., Kühl, H., et al. (2006) Analysis of Myocardial Deformation Based on Pixel Tracking in Two Dimensional Echocardiographic Images Enables Quantitative Assessment of Regional Left Ventricular Function. Heart, 92, 1102-1108. https://doi.org/10.1136/hrt.2005.077107

[12] Saito, K., Okura, H., Watanabe, N., et al. (2009) Comprehensive Evaluation of Left Ventricular Strain Using Speckle Tracking Echocardiography in Normal Adults: Comparison of Three-Dimensional and Two-Dimensional Approaches. Journal of the American Society of Echocardiography, 22, 1025-1030. https://doi.org/10.1016/j.echo.2009.05.021

[13] Onishi, T., Saha, S.K., Delgado-Montero, A., et al. (2015) Global Longitudinal Strain and Global Circumferential Strain by Speckle-Tracking Echocardiography and Feature-Tracking Cardiac Magnetic Resonance Imaging: Comparison with Left Ventricular Ejection Fraction. Journal of the American Society of Echocardiography, 28, 587-596. https://doi.org/10.1016/j.echo.2014.11.018

[14] Orde, S.R., Pulido, J.N., Masaki, M., et al. (2014) Outcome Prediction in Sepsis: 
Speckle Tracking Echocardiography Based Assessment of Myocardial Function. Critical Care, 18, R149. https://doi.org/10.1186/cc13987

[15] Chang, W.T., Lee, W.H., Lee, W.T., et al. (2015) Left Ventricular Global Longitudinal Strain Is Independently Associated with Mortality in Septic Shock Patients. Intensive Care Medicine, 41, 1791-1799. https://doi.org/10.1007/s00134-015-3970-3

[16] Li, Y., Li, H., Zhu, S., et al. (2020) Prognostic Value of Right Ventricular Longitudinal Strain in Patients with COVID-19. JACC: Cardiovascular Imaging, 13, 22872299. https://doi.org/10.1016/j.jcmg.2020.04.014

[17] World Medical Association (2013) World Medical Association Declaration of Helsinki: Ethical Principles for Medical Research Involving Human Subjects. JAMA, 310, 2191-2194. https://doi.org/10.1001/jama.2013.281053

[18] Lang, R.M., Badano, L.P., Mor-Avi, V., Afilalo, J., Armstrong, A., Ernande, L., et al. (2015) Recommendations for Cardiac Chamber Quantification by Echocardiography in Adults: An Update from the American Society of Echocardiography and the European Association of Cardiovascular Imaging. Journal of the American Society of Echocardiography, 8, 1-39. https://doi.org/10.1016/j.echo.2014.10.003

[19] Geyer, H., Caracciolo, G., Abe, H., Wilansky, S., Carerj, S., Gentile, F., Nesser, H.J., Khandheria, B., Narula, J. and Sengupta, P.P. (2010) Assessment of Myocardial Mechanics Using Speckle Tracking Echocardiography: Fundamentals and Clinical Application. Journal of the American Society of Echocardiography, 23, 351-369. https://doi.org/10.1016/j.echo.2010.02.015

[20] Reant, P., Labrousse, L., Lafitte, S., Bordachar, P., Pilliois, X., Tariosse, L., Bonoron-Adele, S., Padois, P., Deville, C., Roudaut, R. and Dos Santos, P. (2008) Experimental Validation of Circunferencial, Longitudinal and Radial 2-Dimensional Strain during Dobutamine Stress Echocardiography in Ischemic Conditions. Journal of the American College of Cardiology, 51, 149-157. https://doi.org/10.1016/j.jacc.2007.07.088

[21] Bansal, M., Cho, G.Y., Chan, J., Leano, R., Haluska, B.A. and Marwick, T.H. (2008) Feasibility and Accuracy of Different Techniques of Two Dimensional Speckle Based Strain and Validation with Harmonic Phase Magnetic Resonance Imaging. Journal of the American Society of Echocardiography, 21, 1318-1325.

https://doi.org/10.1016/j.echo.2008.09.021

[22] Lima, M.S.M., Villarraga, H.R., Abduch, M.C.D., et al. (2017) Global Longitudinal Strain or Left Ventricular Twist and Torsion? Which Correlates Best with Ejection Fraction? Arquivos Brasileiros de Cardiologia, 109, 23-29.

https://doi.org/10.5935/abc.20170085

[23] Cho, G.Y., Marwick, T., Kim, H.S., Kim, M.K., Hong, K.S. and Oh, D.J. (2009) Global 2-Dimensional Strain as a New Prognosticator in Patients with Heart Failure. Journal of the American College of Cardiology, 54, 618-624. https://doi.org/10.1016/j.jacc.2009.04.061

[24] Sengupta, P.P., Tajik, A.J., Chandrasekaran, K. and Khandheria, B.K. (2008) Twist Mechanics of the Left Ventricle: Principles and Application. JACC: Cardiovascular Imaging, 1, 366-376. https://doi.org/10.1016/j.jcmg.2008.02.006

[25] Puntmann, V.O., Carerj, M.L., Wieters, I., Fahim, M., et al. (2019) Outcomes of Cardiovascular Magnetic Resonance Imaging in Patients Recently Recovered from Coronavirus Disease (COVID-19). JAMA Cardiology, 5, 1265-1273.

[26] Tschöpe, C., Ammirati, E., Bozkurt, B., Caforio, A.L.P., Cooper, L.T., Felix, S.B., Hare, J.M., et al. (2020) Myocarditis and Inflammatory Cardiomyopathy: Current Evidence and Future Directions. Nature Reviews Cardiology, 1-25. 
[27] Seo, Y., Ishizu, T., Enomoto, Y., Sugimori, H., Yamamoto, M., Machino, T., Aonuma, K., et al. (2009) Validation of 3-Dimensional Speckle Tracking Imaging to Quantify Regional Myocardial Deformation. Circulation: Cardiovascular Imaging, 2, 451-459. https://doi.org/10.1161/CIRCIMAGING.109.858480 